\title{
Studying the Reclamation State of the Irrigated Meadow Brown Lands in Araksavan Community of Ararat Region
}

\author{
A.Sh. Eloyan, M.H. Barseghyan, S.H. Daveyan, T.A. Jhangiryan \\ H. Petrosian Scientific Center of Soil Science, Agrochemistry and Melioration, ANAU branch \\ elarev@mail.ru, barseghyanmar83@mail.ru, dasev@mail.ru, tjhangiryan@mail.ru
}

\section{A R T I C L E I N F O}

Keywords:

alkalinization,

hydrolysis,

exchangeable

cation, reclamation,

improvement

\begin{abstract}
A B S T RA C T
Improvement of land reclamation methods and ecological state of the soils is essential for the sustainable development of agriculture in Armenia. The aim of the current work is to study the chemical composition of the irrigated meadowbrown soils with an area of 25 hectares in the village of Araksavan.

The results of the study showed that this land plot is not homogeneous in chemical composition. The studied soils are saline and alkaline, and without any chemical reclamation it is impossible to use them in agriculture. Thus, it is recommended to conduct chemical reclamation activities in the mentioned land area.
\end{abstract}

\section{Introduction}

Improvement of the soils'reclamation state is important for the sustainable development of agriculture in Armenia. The study of negative processes occurring in the lands and the development of preventing measures are global issues the solution of which is determinant for ensuring population with necessary food product.

The solution to these problems has become more complicated over the past period due to global climate warming and improper human economic activity, as a result of which a decrease in crop yield capacity, as well as problems related to the food quality and human health are recorded. Among these negative processes, salinization and alkalinization of lands can be distinguished, which have dynamic nature, and there is a need for continuous research in order to identify the intensity of their development.

\section{Materials and methods}

Experimental plots with 25 ha land area located in the Araksavan community of the Ararat region have served as a study object. The research has been conducted through field and laboratory methods. 9 soil sections were cut on the specified land plot and soil samples were taken at the depth of 0-30, 30-60, 60-100 cm layers from each section to conduct laboratory research.

The soil chemical composition $(\mathrm{pH})$, total amount of 
water-soluble salts, the content of adsorbing complex, the ratio of cations and fluctuations of groundwater level have been studied per months during the year. The studies were conducted in field and laboratory conditions. The chemical composition of the water extract was determined and the general chemical analysis was conducted through the adopted methods (Arinushkina, 1962), $\mathrm{pH}$ was determined via electrode potentiometric method, exchangeable $\mathrm{Ca}$ and $M g$ - with the method of A.N. Baghramyan and A.A. Abrahamyan, absorption capacity - according to Gedroits method (Gedroits, 1929).

\section{Results and discussions}

The results of the laboratory study showed that in the above-noted area at the sections of 1,2 and 3 the lands are not salinized, $\mathrm{pH}$ ranges from 7.5-7.9, the watersoluble salts do not exceed $0.132 \%$, the $\mathrm{CO}_{3}{ }^{2-}$ toxic ion is absent in a meter layer (Table 1). While the results of the chemical composition in the land sections of $4,5,6$, 7,8 and 9 show that in a meter layer the soils are highly alkaline, $\mathrm{pH}$ fluctuates within the range of 9.5-9.7; they are also averagely salinized and the total amount of water-soluble salts is $0.283-0.500 \%$. There is a toxic ion $\mathrm{CO}_{3}{ }^{2-}$ in the medium, the alkaline hydrolysis of which is responsible for the alkaline reaction of the soil solution. The amount of water-soluble $N a$ is also higher than the maximum permissible limit (the permissible amount of water-soluble $\mathrm{Na}$ is $0.75 \mathrm{mg}$-eq/100 g).

Thus, from the study results (Table 1), it becomes obvious that the soils taken from the mentioned sections are saline-alkaline, the medium contains $\mathrm{Na}_{2} \mathrm{CO}_{3}$, without the removal of which it is impossible to cultivate crops in the mentioned lands.

The content and ratio of the soil absorbing complex has been also studied, the data of which are presented in Table 2.

Table 1. The chemical composition of the irrigated meadow soils*

\begin{tabular}{|c|c|c|c|c|c|c|c|c|c|c|}
\hline \multirow{2}{*}{$\begin{array}{c}\text { Section, } \\
\mathbf{n} / \mathbf{n}\end{array}$} & \multirow{2}{*}{$\begin{array}{c}\text { Depth, } \\
\text { cm }\end{array}$} & \multirow{2}{*}{ pH } & \multirow{2}{*}{$\begin{array}{c}\text { Salts, } \\
\%\end{array}$} & \multicolumn{7}{|c|}{ Water-soluble ions, $\mathrm{mg-eq} / 100 \mathrm{~g}$ soil } \\
\hline & & & & $\mathrm{CO}_{3}^{2-}$ & $\mathrm{HCO}_{3}^{-}$ & $\mathrm{Cl}^{-}$ & $\mathrm{SO}_{4}^{2-}$ & $\mathrm{Ca}^{2+}$ & $\mathrm{Mg}^{2+}$ & $\mathrm{Na}^{++} \mathrm{K}^{+}$ \\
\hline \multirow{3}{*}{1} & $0-30$ & 7.7 & 0.111 & - & 1.00 & 0.20 & 0.28 & 0.35 & 0.32 & 0.81 \\
\hline & $30-50$ & 7.8 & 0.105 & - & 1.00 & 0.31 & 0.10 & 0.35 & 0.24 & 0.82 \\
\hline & $50-100$ & 7.9 & 0.126 & - & 1.20 & 0.11 & 0.35 & 0.25 & 0.48 & 0.93 \\
\hline \multirow{3}{*}{2} & $0-30$ & 7.8 & 0.132 & - & 1.11 & 0.51 & 0.21 & 0.55 & 0.40 & 0.88 \\
\hline & $30-50$ & 7.7 & 0.126 & - & 1.03 & 0.45 & 0.25 & 0.45 & 0.32 & 0.96 \\
\hline & $50-100$ & 7.6 & 0.116 & - & 1.00 & 0.45 & 0.21 & 0.65 & 0.48 & 0.53 \\
\hline \multirow{3}{*}{3} & $0-30$ & 7.5 & 0.103 & - & 0.97 & 0.28 & 0.17 & 0.55 & 0.40 & 0.47 \\
\hline & $30-50$ & 7.6 & 0.109 & - & 1.00 & 0.31 & 0.22 & 0.55 & 0.48 & 0.50 \\
\hline & $50-100$ & 7.6 & 0.108 & - & 1.00 & 0.37 & 0.19 & 0.50 & 0.40 & 0.66 \\
\hline \multirow{3}{*}{4} & $0-30$ & 9.7 & 0.432 & 3.59 & 4.20 & 0.73 & 0.56 & 0.50 & 0.16 & 4.83 \\
\hline & $30-50$ & 9.5 & 0.500 & 3.21 & 4.81 & 0.99 & 0.58 & 0.30 & 0.16 & 5.92 \\
\hline & $50-100$ & 9.2 & 0.458 & 2.40 & 4.12 & 0.99 & 0.82 & 0.25 & 0.24 & 5.44 \\
\hline \multirow{3}{*}{5} & $0-30$ & 9.3 & 0.437 & 2.27 & 4.25 & 0.76 & 0.58 & 0.55 & 0.32 & 4.72 \\
\hline & $30-50$ & 9.2 & 0.439 & 2.27 & 4.33 & 0.85 & 0.44 & 0.45 & 0.32 & 4.85 \\
\hline & $50-100$ & 9.7 & 0.477 & 2.79 & 3.53 & 2.00 & 0.92 & 0.30 & 0.08 & 6.07 \\
\hline \multirow{3}{*}{6} & $0-30$ & 9.4 & 0.449 & 0.93 & 3.53 & 1.80 & 0.90 & 0.30 & 0.32 & 5.61 \\
\hline & $30-50$ & 9.5 & 0.333 & 2.00 & 2.72 & 1.21 & 0.52 & 0.30 & 0.24 & 3.91 \\
\hline & $50-100$ & 9.1 & 0.328 & 1.94 & 2.64 & 1.21 & 0.57 & 0.40 & 0.32 & 3.70 \\
\hline \multirow{3}{*}{7} & $0-30$ & 9.1 & 0.359 & 1.77 & 2.72 & 1.27 & 0.88 & 0.50 & 0.40 & 3.97 \\
\hline & $30-50$ & 8.6 & 0.336 & 1.84 & 2.80 & 1.27 & 0.49 & 0.30 & 0.32 & 3.94 \\
\hline & $50-100$ & 8.6 & 0.283 & 1.67 & 2.20 & 1.04 & 0.71 & 0.40 & 0.32 & 3.23 \\
\hline \multirow{3}{*}{8} & $0-30$ & 8.5 & 0.294 & 1.90 & 2.36 & 1.61 & 0.50 & 0.50 & 0.48 & 3.49 \\
\hline & $30-50$ & 8.8 & 0.397 & 2.00 & 2.84 & 1.5 & 0.90 & 0.40 & 0.32 & 4.77 \\
\hline & $50-100$ & 8.8 & 0.394 & 2.00 & 2.76 & 1.75 & 0.88 & 0.50 & 0.32 & 4.57 \\
\hline \multirow{3}{*}{9} & $0-30$ & 8.9 & 0.391 & 1.24 & 2.64 & 1.92 & 0.86 & 0.40 & 0.32 & 4.70 \\
\hline & $30-50$ & 9.2 & 0.446 & 2.17 & 3.80 & 1.52 & 0.62 & 0.40 & 0.46 & 5.38 \\
\hline & $50-100$ & 9.4 & 0.478 & 3.13 & 4.00 & 1.61 & 0.60 & 0.55 & 0.48 & 5.18 \\
\hline
\end{tabular}

*Composed by the authors. 
Table 2. The composition of absorbed cations*

\begin{tabular}{|c|c|c|c|c|c|c|c|c|c|c|}
\hline \multirow{2}{*}{$\begin{array}{l}\text { Section, } \\
\mathbf{n} / \mathbf{n}\end{array}$} & \multirow{2}{*}{$\begin{array}{l}\text { Depth, } \\
\text { cm }\end{array}$} & \multicolumn{4}{|c|}{$\begin{array}{l}\text { Absorbed cations, } \\
\text { mg-eq per } 100 \mathrm{~g} \text { soil }\end{array}$} & \multirow{2}{*}{$\begin{array}{c}\text { Total, } \\
\text { mg-eq/100 g } \\
\text { soil }\end{array}$} & \multicolumn{4}{|c|}{$\begin{array}{c}\text { Absorbed cations, } \\
\%\end{array}$} \\
\hline & & $C a$ & $M g$ & $N a$ & $K$ & & $C a$ & $M g$ & $N a$ & $\boldsymbol{K}$ \\
\hline \multirow{3}{*}{1} & $0-30$ & 25.6 & 18.7 & 1.00 & 1.1 & 46.4 & 55.2 & 40.3 & 2.1 & 2.4 \\
\hline & $30-50$ & 22.1 & 18.8 & 2.1 & 1.1 & 44.1 & 50.1 & 42.6 & 4.8 & 2.5 \\
\hline & $50-100$ & 23.1 & 20.0 & 1.5 & 1.1 & 45.7 & 50.5 & 43.8 & 3.3 & 2.4 \\
\hline \multirow{3}{*}{2} & $0-30$ & 22.4 & 19.6 & 1.9 & 1.3 & 45.2 & 49.6 & 43.4 & 4.2 & 2.8 \\
\hline & $30-50$ & 23.7 & 20.08 & 2.0 & 1.0 & 46.8 & 50.6 & 43.0 & 4.3 & 2.1 \\
\hline & $50-100$ & 23.0 & 21.02 & 2.0 & 1.8 & 47.8 & 48.1 & 43.9 & 4.2 & 3.8 \\
\hline \multirow{3}{*}{3} & $0-30$ & 22.4 & 20.0 & 1.6 & 1.6 & 45.6 & 49.1 & 43.9 & 3.5 & 3.5 \\
\hline & $30-50$ & 21.9 & 19.6 & 1.3 & 1.1 & 43.9 & 50.0 & 44.6 & 2.9 & 2.5 \\
\hline & $50-100$ & 20.3 & 21.1 & 1.5 & 1.1 & 44.0 & 46.1 & 48.0 & 3.4 & 2.5 \\
\hline \multirow{3}{*}{4} & $0-30$ & 12.5 & 9.2 & 13.1 & 0.8 & 35.6 & 35.1 & 25.8 & 36.9 & 2.2 \\
\hline & $30-50$ & 15.0 & 7.4 & 13.5 & 1.1 & 37.0 & 40.5 & 20.0 & 36.5 & 3.0 \\
\hline & $50-100$ & 13.0 & 6.1 & 13.0 & 1.2 & 33.3 & 39.0 & 18.4 & 39.0 & 3.6 \\
\hline \multirow{3}{*}{5} & $0-30$ & 13.3 & 8.5 & 7.2 & 1.2 & 30.2 & 44.4 & 28.1 & 23.8 & 4.0 \\
\hline & $30-50$ & 12.5 & 7.4 & 11.6 & 1.4 & 32.9 & 41.1 & 24.3 & 35.2 & 4.2 \\
\hline & $50-100$ & 12.5 & 7.4 & 9.4 & 0.8 & 30.1 & 41.4 & 24.7 & 31.4 & 2.5 \\
\hline \multirow{3}{*}{6} & $0-30$ & 13.3 & 5.2 & 12.1 & 1.0 & 31.6 & 42.0 & 16.5 & 38.3 & 3.2 \\
\hline & $30-50$ & 13.7 & 5.6 & 12.3 & 1.2 & 32.8 & 41.8 & 17.1 & 37.5 & 3.6 \\
\hline & $50-100$ & 13.1 & 5.1 & 11.4 & 1.0 & 30.6 & 42.8 & 16.7 & 37.2 & 3.3 \\
\hline \multirow{3}{*}{7} & $0-30$ & 14.6 & 9.0 & 8.6 & 0.9 & 33.1 & 44.1 & 27.1 & 26.0 & 2.8 \\
\hline & $30-50$ & 12.1 & 8.8 & 8.4 & 0.6 & 29.9 & 40.5 & 29.3 & 28.2 & 2.0 \\
\hline & $50-100$ & 13.4 & 7.4 & 11.9 & 1.0 & 33.7 & 39.7 & 22.0 & 35.3 & 3.0 \\
\hline \multirow{3}{*}{8} & $0-30$ & 13.7 & 5.6 & 12.0 & 1.1 & 32.4 & 42.2 & 17.3 & 37.1 & 3.4 \\
\hline & $30-50$ & 13.9 & 6.7 & 11.0 & 1.1 & 32.7 & 42.6 & 20.4 & 33.8 & 3.2 \\
\hline & $50-100$ & 15.3 & 6.2 & 9.4 & 0.9 & 31.8 & 48.1 & 19.5 & 29.5 & 2.9 \\
\hline \multirow{3}{*}{9} & $0-30$ & 18.3 & 6.1 & 10.7 & 1.3 & 36.4 & 50.2 & 16.8 & 29.5 & 3.5 \\
\hline & $30-50$ & 15.4 & 5.6 & 9.2 & 1.1 & 31.3 & 49.2 & 17.9 & 29.3 & 3.6 \\
\hline & $50-100$ & 16.1 & 6.3 & 9.4 & 1.3 & 33.1 & 48.6 & 19.0 & 28.4 & 4.0 \\
\hline
\end{tabular}

*Composed by the authors.

In the soil sections of 1,2 and 3 the amount of $\mathrm{Ca}$ dominates in the content of exchangeable cations, which makes $60 \%$ of the total exchangeable cations, but the amount of absorbed $\mathrm{Mg}$ is higher than the maximum permissible limit (the permissible limit of absorbed $\mathrm{Mg}$ is up to $30 \%$ ), while the amounts of absorbed $\mathrm{Na}$ and $\mathrm{K}$ are within the permissible limits (>5\%).

Thus, in the specified sections the soils are characterized by the ratio of exchange cations unfavorable for crops growth and development, which can be improved by reducing the amount of $\mathrm{Mg}$ absorbed (Papinyan, 1977). In case of such ratio of absorbing complex, the crop yield capacity declines.

In the sections of 4, 5, 6, 7, 8 and 9 the amount of absorbed $\mathrm{Na}$ predominates in the content of absorbing complex, ranging from 7.2-13.5 mg-eq (the permissible amount of absorbed $\mathrm{Na}$ is $2.25 \mathrm{mg}$-eq), which makes $23.8-36.5 \%$ of the total amount of absorbed cations.

The data on the groundwater level received throughout 2020 for the studied area of Araksavan community are introduced in Table 3. 
Table 3. The mean indicators of groundwater levels*

\begin{tabular}{|c|c|c|c|c|c|c|c|c|c|c|c|c|}
\hline Location & 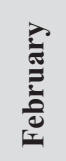 & 竞 & $\frac{\bar{z}}{2}$ & $\vec{i}$ & $\stackrel{\Xi}{\Xi}$ & 를 & 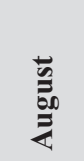 & 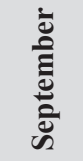 & 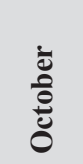 & 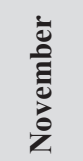 & 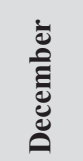 & $\begin{array}{c}2020 \\
\text { annual, } \\
\mathbf{m}\end{array}$ \\
\hline Araksavan & 1.7 & 1.47 & 1.75 & 1.57 & 1.47 & 1.87 & 2.13 & 1.83 & 1.76 & 1.83 & 1.72 & 1.74 \\
\hline
\end{tabular}

To estimate the fluctuations of groundwater levels a diagram has been also designed (Figure).

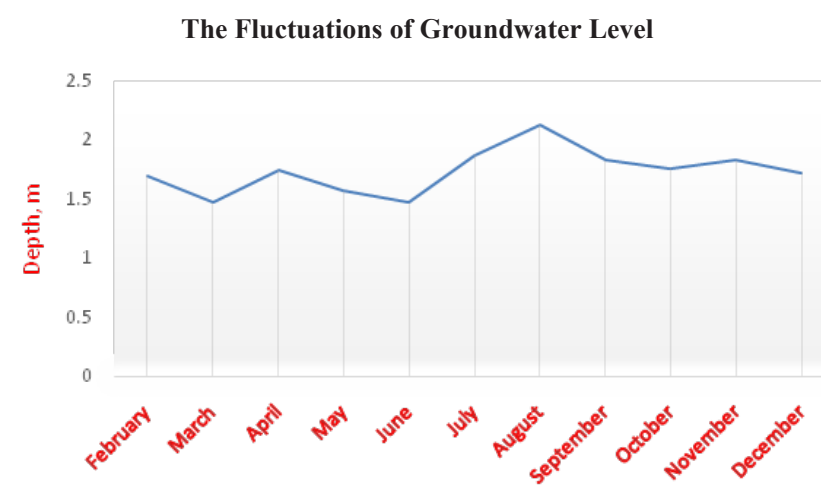

Figure. Diagram for groundwater level fluctuations (composed by the authors).

As the diagram shows, the groundwater level is quite high, as a result of which salinization processes are observed. In the spring months, its level mainly rises up to $1.47 \mathrm{~m}$, and from July it begins to decrease due to climate warming, increase of the use rates of deep waters, etc. It reached its lowest level in August $(2.13 \mathrm{~m})$. Groundwater levels fluctuate very little during the autumn months (almost unchanged).
The average annual depth is $1.74 \mathrm{~m}$. Groundwater level fluctuations during the year make about $0.66 \mathrm{~m}$.

\section{Conclusion}

Thus, upon the laboratory and field research studies conducted along the 25 ha experimental plot of the Araksavan community, it can be concluded that the ratio of exchange cations in the sections of 1,2 and 3 is not favorable for the growth and development of crops. Thus, to improve the situation, it is recommended to use $\mathrm{Ca}$ containing compounds. Besides, in the sections of 4, 5, 6, 7, 8 and 9 it is necessary to implement chemical reclamation, otherwise it will be impossible to cultivate crops.

\section{References}

1. Arinushkina, E.V. (1962). Guidance for Soil Chemical Analysis, Moscow, - 492 p. (in Russian).

2. Gedroits, K.K. (1929). A Universal Method for Determining the Exchange Capacity of Soils, Ed. 5, - Vol. V1l, - pp. 451-454.

3. https://www.armstat.am (accessed on 20.07.2021).

4. Papinyan, V.A. (1977b). Changes in the Composition of Exchange Cations in Carbonate Saline Alkaline Soils of the Arazdayan Steppe during their Reclamation // Bulletin of Soil Science, Institute after V.V. Dokuchaev, - M. Edition 15, - pp. 57-64. 